\title{
Depresión y ansiedad como factores de riesgo en ideación suicida en pacientes con adicciones del Centro Nacional de Control de Adicciones de Asunción, Año 2017
}

\author{
Samuel Ysaac Marengo Velázquez¹, Juan Sebastián Bogado Aquino
}

\section{Resumen}

Introducción: Según la Organización Mundial de la Salud (OMS) la adicción es una enfermedad física y psicoemocional que crea una dependencia hacia una sustancia, actividad o relación. En el subcontinente Sudamericano esto se ha vuelto un problema muy grande, ya que no solo está en el consumo, sino en la producción, pues es Sudamérica el máximo productor de drogas en el mundo. En Paraguay las adicciones son un problema que cada vez más se acrecienta y no tiene distinción de clases, pues afecta absolutamente a todos los estratos de la sociedad. El país cuenta con una institución pública bajo la tutela del Ministerio de Salud Pública y Bienestar Social (MSPBS), que es el único abocado al tratamiento integral de las personas con problemas de adicción que es el Centro Nacional de Control de Adicciones (CNCA).

La ansiedad y la depresión son factores de riesgo para la ideación suicida, entiéndase por ideación suicida como pensamiento reiterativo y persistente de autoprovocarse la muerte y en los pacientes en estados de adicción estos son más pronunciados sobre todo en el periodo desintoxicación.

Objetivo: Analizar la depresión y ansiedad como factores de riesgo en la ideación suicida en pacientes con adicción del Centro Nacional de Control de Adicciones, en Asunción, en el mes de septiembre del 2017.

Material y Método: El estudio se realizó con un diseño no experimental, de alcance transversal, con enfoque cuantitativo, tomando como población a todos los adultos internados en el mes de septiembre en el Centro Nacional de Control de Adicciones, que fueron 7 , y por la cantidad de los participantes no se tomó muestra, sino se utilizó el método de censo, los instrumentos utilizados fueron: cuestionario tipo Likert creado por los autores de la investigación, el BDI - II (Inventario de Depresión de Beck, IDARE (Inventario de Ansiedad Rasgo - Estado), y el test de EBIS (Escala de Ideación Suicida de Beck). Las variables que se tuvieron en cuenta: adicción, ideación suicida, ansiedad, depresión.

Resultados: En cuanto a las edades 43\% tenía 18 años, 29\% con 19 años, 14\% con 20 años y otro $14 \%$ con 23 años, de los mismos pacientes el $86 \%$ llevaba internado menos

1. Carrera de Psicología, Facultad de Ciencias Humanísticas y de la Educación, Universidad Iberoamericana, Paraguay.

Trabajo de Tesis de Grado.

E-mail: samumarengo@hotmail.com

DOI: 10.26885/rcei.foro.2017.135 
de un mes, y el $14 \%$ más de 5 meses, en cuanto al consumo; las sustancias preferidas son, con el 86\%, "la marihuana", "el cigarrillo" y "la cocaína", "alcohol" un 57\% de consumo, $29 \%$ "otras drogas", y 14\% la "cola de zapatero", cada paciente en promedio consumía por lo menos 4 sustancias distintas con una frecuencia de consumo de "todos los días" por el $57 \%$ de ellos, el 29\% " 2 a 3 veces por semana" y el $14 \%$ "una vez por semana", y el tiempo de consumo fue de "más de tres años" por el $86 \%$ de quienes participaron y el 14\% "menos de 6 meses", según resultados obtenidos por el cuestionario realizado. En cuanto a los niveles de ansiedad obtenidos tras la aplicación del test IDARE, en Ansiedad como Estado, los datos fueron, 86\% "moderado", 14\% "alto"; en Ansiedad como Rasgo, 57 \% "alto", 43\% "moderado", tras la aplicación del test BDI-II, los niveles de depresión obtenidos fueron; 29\% "normal", 14\% "leve alteración del estado de ánimo", 29\% "intermitente", 14\% "moderado" y 14\% "extremo". Para determinar la ideación Suicida, el instrumento utilizado fue el EBIS, cuyos resultados fueron $43 \%$ de los pacientes "con ideación suicida", y $56 \%$ de los mismos "sin ideación suicida".

Conclusiones: Se encontró como características de los pacientes, un promedio de edad de entre 18 y 19 años, el tiempo de consumo es mayor a 3 años y el inicio de consumo de los mismos se da en un promedio de los 16 años. Entre las drogas más consumidas las preferidas por los mismos fueron, el cigarrillo, la Marihuana y la Cocaína, con un 86\% de consumo de cada uno.

La totalidad de los pacientes poseen ansiedad en niveles mayores al rango normal, en concordancia con el periodo de abstinencia. En cuanto a depresión, el 28 \% arrojó un nivel moderado, $14 \%$ extrema. El $43 \%$ de los participantes han presentado Ideación Suicida versus el $51 \%$ de los mismos que no lo han presentado. Se encontró que existe una relación entre la ideación suicida, la ansiedad y la depresión, pues de los pacientes con ideación suicida el $67 \%$ posee depresión vs un $50 \%$ en los que no tienen ideación, en ambos la totalidad con Ansiedad.

Se recomienda poder hacer un trabajo interdisciplinario especialmente con las familias de las personas drogodependientes, para que estas puedan proveer de apoyo y sostén a los mismos, y en el área educativa de modo a que los jóvenes conozcan a fondo esta problemática y ya no sea un "tabú" dentro de la sociedad. A la sociedad paraguaya, cambiar las referencias hacia ellos, ya que, los términos que se utilizan para con los mismos son muy peyorativos como "drogadictos", sino más bien referirlos como personas drogodependientes, o personas en estado de adicción. Proveer de más oportunidades laborales como forma de reinserción social, ya que es un aporte de mucha importancia para su proceso de recuperación. Realizar investigaciones de las mejores estrategias terapéuticas de mayor aceptación y resultados tanto para las adicciones como para la ideación suicida.

Palabras clave: adicción, ideación suicida, depresión, ansiedad, niveles.

\section{Referencias}

American Psychiatric Association. (2014). Manual diagnóstico y estadístico de los trastornos mentales. Madrid, España: Panamericana. 
Depresión y ansiedad como factores de riesgo en ideación suicida. Marengo y Bogado

Álvaro Valdivia, P. (2015). Suicidología: prevención, tratamiento psicológico einvestigación de procesos suicidas. Lima: Editorial UPC.

Organización Panamericana de la Salud. (2016). Prevención de la conducta suicida. Washington DC: Itzhak Levav. 